\title{
The effect of fluid redox potential on kerogen pyrolysis at elevated temperatures and pressures
}

\author{
Y.N. YANG ${ }^{1}$, N.N. ZHONG ${ }^{1}$, J. WU ${ }^{1}$, L.J. HUANG ${ }^{1}$
}

${ }^{1}$ China University of Petroleum-Beijing, 18 Fuxue Road, Changping, 102249, Beijing, China (*correspondence: nnzhongxp@cup.edu.cn)

\section{Experimental Method}

The experiments reported here differ from most laboratory investigations of kerogen pyrolysis because mineral assemblages that could buffer different and geologically reasonable redox state of fluid were contained in the experiments. This approach allows the kerogen pyrolysis to be interpreted within both a thermodynamic and kinetic framework [1] thus a deeper understanding of the kerogen pyrolysis and organic-inorganic interaction can be made.

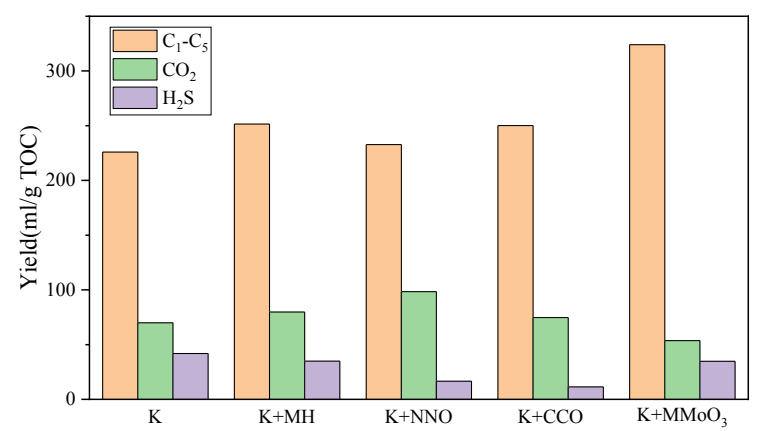

Figure 1: The gas yields variation with decreasing mineralassemblages-buffered fluid redox potential.

\section{Discussion of Results}

The experimental results above clearly show that the kerogen pyrolysis is controlled by the redox potential of the fluid. Higher amount of reducing carbon compounds $\left(\mathrm{C}_{1}-\mathrm{C}_{5}\right.$ hydrocarbon gas) and lower amount of oxidizing carbon compounds $\left(\mathrm{CO}_{2}\right)$ are generated with decreasing redox potential of the fluid, which is identical with Helgeson's (2009) theorical calculation result [2]. This indicates that kerogen pyrolysis is not only kinetically but thermodynamically controlled. The fluid redox potential is an important factor for considering kerogen pyrolysis.

[1]Seewald et al. (2001) Geochimica et Cosmochimica Acta 65(10), 1641-1664. [2] Helgeson et al. (2009) Geochimica et Cosmochimica Acta 73(3), 594-695. 